\author{
Wawrzyniec Rudolf, Wioletta Krawiec, Kamila Szymańska \\ Uniwersytet Łódzki \\ e-mails: wawrzyniec.rudolf@uni.lodz.pl; krawiecwioletta@gmail.com; \\ szymanska.km@gmail.com
}

\title{
STUDIUM PRZYPADKU JAKO METODA \\ BADANIA RELACJI MIĘDZYORGANIZACYJNYCH \\ W MARKETINGOWYM PROCESIE BUDOWANIA \\ MARKI TERYTORIUM W OPARCIU O KULTURE - KONCEPCJA BADAŃ
}

\section{CASE STUDY AS A METHOD OF STUDYING INTER-ORGANIZATIONAL RELATIONS IN THE MARKETING PROCESSES OF BUILDING A PLACE BRAND BASED ON CULTURE - CONCEPT OF THE RESEARCH}

DOI: $10.15611 /$ pn.2018.525.24

JEL Classification: R58, M37, H75

Streszczenie: Artykuł ma na celu przybliżenie znaczenia specyfiki wykorzystania studium przypadku (case study) jako metody badawczej pozwalającej na opisanie relacji międzyorganizacyjnych w marketingowym procesie budowania marki miasta i regionu w oparciu o kulturę. Badania mają na celu identyfikację determinant wpływających na skuteczną współpracę administracji samorządowej (urząd miasta, urząd marszałkowski) z instytucjami kultury (muzea, ośrodki kultury, teatry itd.) w kontekście realizacji procesów marketingowych zorientowanych na budowanie marki terytorium w oparciu o kulturę. Projekt ma też na celu określenie motywów nawiązywania i utrzymywania relacji współpracy z perspektywy miejskich i regionalnych instytucji kultury oraz samorządowej administracji publicznej. Opracowanie ma charakter pracy koncepcyjnej.

Słowa kluczowe: metoda studium przypadku, relacje międzyorganizacyjne, budowanie marki terytorium, polityka rozwoju kultury.

Summary: The article aims to present the significance of the use of a case study as a research method allowing to describe inter-organizational relations in the marketing process of building a place brand based on culture. The research aims to identify determinants affecting the effective cooperation of self-government administration (city hall, marshal office) with cultural institutions (museums, cultural centres, theatres) in the context of marketing processes oriented on building the territorial brand based on culture. The project is also aimed at identi- 
fying the motives for establishing and maintaining cooperation relations from the perspective of urban and regional cultural institutions and self-government public administration. The study is a conceptual work.

Keywords: case study method, inter-organisational relations, place branding, culture development policy.

\section{Wstęp}

Najbardziej popularnym nurtem w marketingu terytorialnym jest ten zajmujący się procesami kreowania marki terytorialnej [Kavaratzis 2004; Glińska 2016]. Autorzy podejmują badania dotyczące gmin, miast, powiatów, regionów czy całych krajów, zorientowane na poznanie czynników optymalizujących ich rozpoznawanie i pozytywne asocjacje. W ostatnich latach zwrócono uwagę na partycypacyjny charakter procesu budowania marki miasta, co w literaturze nazywane jest też brandingiem uczestniczącym [Kavaratzis 2012]. Badania pokazują, że aktywne angażowanie mieszkańców czy innych interesariuszy w ten proces zwiększa skuteczność i efektywność podejmowanych działań wizerunkowych [Klijn, Eshuis, Braun 2012; Glińska 2017]. W opracowaniu podjęto natomiast komplementarną do wspomnianej problematykę angażowania interesariuszy instytucjonalnych miasta i regionu w procesy budowania marki terytorium.

Chcąc zawęzić obszar badawczy, zdecydowano się na wybór kultury jako treści przekazu, na którym budowane są działania wizerunkowe. Jest to tematyka często pojawiająca się w treści przekazów promocyjnych terytoriów, jako że stanowi o tożsamości lokalnej czy regionalnej społeczności. W badaniu podjęto wątek zakresu wykorzystania przez miasta i regiony potencjału lokalnych instytucji kultury (IK) do realizacji procesów wizerunkowych. Wejście w problematykę budowania relacji na linii administracja samorządowa - instytucje kultury ma pozwolić na pełniejsze poznanie wpływu działań marketingowych terytorium na ich kształtowanie.

Ze względu na eksploracyjny charakter planowanych badań zdecydowano się wykorzystać metodę wielokrotnego studium przypadku osadzonego w kontekście lokalnego (miasto) i regionalnego (region) rynku kultury, a wymiar metodyczny badania stanowi główny wątek niniejszego artykułu.

\section{Teoretyczne podejścia do badania relacji międzyorganizacyjnych}

W literaturze mówi się o trzech perspektywach do współpracy: optymistycznej (optymist), pesymistycznej (pessimist) i realistycznej (realist) [Sullivan, Skelcher 2002], gdzie dla każdej z nich wskazuje się inne teorie opisujące te relacje. Dla perspektywy optymistycznej, w której poszczególni uczestnicy relacji motywowani optymizmem i entuzjazmem przystępują do współpracy, teorie opisujące to: Collaborative 
empowerment theory oraz Regime theory. W przypadku perspektywy pesymistycznej, gdzie poszczególni uczestnicy relacji przystąpienie do niej traktują jako interes (korzystny bilans wymiany zasobów), teorią opisującą jest Resource dependency theory. Natomiast w przypadku perspektywy realistycznej adekwatną teorią opisującą współpracę jest Evolutionary theory. Podjęcie szerszych badań dotyczących budowania relacji międzyorganizacyjnych na rynku instytucji publicznych w Polsce wymaga zatem poznania motywów wchodzenia publicznych uczestników rynków: kultury, edukacji, ochrony zdrowia itd. w procesy współpracy. Dopiero bliższe poznanie tych motywów i zakresu angażowania się we współpracę instytucji publicznych na danym rynku usług publicznych (tu: rynku kultury) pozwoli na wskazanie właściwej teorii opisującej te relacje i na sformułowanie nawiązujących do niej hipotez dla testowania w badaniach ilościowych na grupie reprezentatywnej. Współpraca, nazywana również partnerstwem, współdziałaniem czy kooperacją [Rudolf 2016], staje się nabierającym coraz większego znaczenia instrumentem podnoszenia skuteczności i efektywności instytucji publicznych, zarówno w modelu New Public Management, jak i w modelu Public Governance [Anders-Morawska, Rudolf 2015]. Dla rozstrzygnięcia, która teoria opisuje relacje pomiędzy instytucjami publicznymi, należy ustalić motywy wchodzenia w związki, co jest trudne do zrealizowania poprzez proste badania oparte na instrumentach sondażowych. Prawdziwe motywy mogą pozostawać ukryte, a ich ustalenie jest możliwe tylko poprzez badania jakościowe, które zostały zaplanowane w niniejszym projekcie.

Zarządzanie relacjami między administracją publiczną a instytucjami kultury jest także silnie zakorzenione $\mathrm{w}$ idei marketingu wartości dostarczanej wielu interesariuszom. W związku ze swoim wkładem w budowanie marki terytorium i organizację wydarzeń kulturalnych oczekują oni bowiem również określonych korzyści (aby móc analizować relacje między nakładami i korzyściami wskazujące na wartość) [Smith, Colgate 2007].

Koncepcja marketingu wartości przedstawiona przez Doyle'a [2003] odnosi się głównie do budowania relacji z klientami zewnętrznymi (niezależnie, czy mówimy o obszarze B2B, czy B2C). Wydaje się, że można ją także bezpośrednio zastosować w odniesieniu do relacji między współpracującymi organami administracji i instytucjami kultury w kontekście działań na rzecz kreowania marki terytorium. Warto też pamiętać, że wypracowanie korzyści dla tych dwóch współpracujących stron wiąże się również z oferowaniem wartości dla innych partnerów biznesowych (np. mediów, NGO-sów, firm itd.), a nade wszystko - dla uczestnika wydarzeń kulturalnych, będącego mieszkańcem miasta lub turystą. Ponadto przy budowaniu relacji ukierunkowanych docelowo na usatysfakcjonowanie i budowanie lojalności klienta zewnętrznego (finalnego) należy pamiętać o efekcie synergii płynącym ze współpracy podmiotów instytucjonalnych. Nie można bowiem odgórnie zakładać, że pojedynczy podmiot, np. instytucja kultury, nie byłby w stanie samodzielnie dostarczyć wartości klientom (uczestnikom wydarzeń), ale dzięki partnerstwu te wartości mogą być bardziej zróżnicowane, a także bazować na większych zasobach i wzajemnej 
inspiracji do rozwoju. Takie spojrzenie na zarządzanie zgodnie $\mathrm{z}$ ideą marketingu wartości skłania do rozważań na temat bezpośrednich i pośrednich efektów budowania partnerskich relacji.

\section{Studium przypadku jako metoda badania procesów zarządzania w administracji publicznej}

\subsection{Studium przypadku jako metoda badawcza - okoliczności stosowania}

Metoda studium przypadku stosowana jest najczęściej w sytuacjach, gdy problem badawczy obejmuje dużą liczbę zmiennych o złożonych wzajemnych relacjach, a badacz ma bardzo ograniczoną kontrolę nad analizowanym obiektem [Eisenhardt 1989; Yin 2009]. Studium przypadku najczęściej jest wykorzystywane wtedy, gdy chcemy m.in.:

- wyjaśnić związki przyczynowo-skutkowe, które mogą być zbyt złożone dla badań ankietowych i niemożliwe do przeanalizowania na drodze eksperymentu (zbyt duża kontrola nad przebiegiem badania),

- przeanalizować podjęte działania i uzyskane efekty pewnego programu lub polityki z punktu widzenia ich skuteczności i efektywności,

- zbadać efekty pewnego rodzaju wydarzeń, programów lub polityk, które nie mają ścisłego i łatwego do przewidzenia zbioru rezultatów,

- szczegółowo opisać kontekst, w którym zaszło (lub zachodzi) określone zjawisko interesujące badacza [Patton, Appelbaum 2003].

Najważniejszą zaletą metody studium przypadku, stosowanej w dziedzinie nauk ekonomicznych i zarządzania, jest możliwość uzyskania rezultatów o dużym znaczeniu praktycznym dla menedżerów, przedsiębiorców, akcjonariuszy i innych osób działających w sferze gospodarki. Pod tym względem metoda ta wydaje się lepsza niż podejścia ilościowe, które bywają krytykowane za niską praktyczną wartość wyników i powiększanie luki pomiędzy oczekiwaniami praktyków a tym, co mają do zaoferowania naukowcy.

Na podstawie literatury przedmiotu można zaobserwować, że wielu badaczy potrafi dostrzec rolę i przydatność case study do kreowania rozwoju nauki, w tym nauk o zarządzaniu. Można tu wymienić prace takich autorów, jak: Yin [2009], Stake [1995], Eisenhardt [1989], Sudoł [2012], Dul i Hak [2008], Perry [1998] i inni. Jednakże na potrzeby dalszych rozważań autorzy artykułu przyjmują sposób wykorzystania case study do badań opracowany przez Yina. Wymienia on takie etapy opracowywania studium przypadku, jak: projektowanie, przygotowanie, zbieranie, analizowanie, upowszechnianie. Zostały one omówione w części koncepcyjnej artykułu. 


\subsection{Wykorzystanie studium przypadku w odniesieniu do badania funkcjonowania administracji publicznej}

Administracja publiczna to obszar badawczy, wobec którego wykorzystywano metodę studium przypadku już wiele dekad temu [Stein 1952]. Z czasem początkowe podejście, koncentrujące się na pogłębionej analizie jednego przypadku, ustępowało bardziej złożonym odmianom tej metody. Zaczęło zyskiwać na popularności podejście wykorzystujące porównawcze studia przypadków. Agranoff i Radin [1991, s. 203-231] w przekonujący sposób zaprezentowali ich przydatność do badań funkcjonowania administracji publicznej, podkreślając, że jest to metoda szczególnie potrzebna w przypadku dużej złożoności kontekstu obserwowanych zjawisk. Autorzy ci wymienili też pewne mankamenty tej metody. Dostrzegli m.in. złożoność procesów pozyskiwania respondentów do badań pogłębionych, które okazują się bardzo czasochłonne (wywiady pogłębione, dyskusje grupowe).

Kolejnym krokiem jest wzrost popularności wielokrotnych studiów przypadku w zarządzaniu publicznym, co zostało szczególnie zauważone w kontekście podejmowania przez badaczy problematyki governance, dotyczącej uspołecznienia procesów publicznych i budowania relacji międzyorganizacyjnych. Interesującym opracowaniem, ukazującym skalę zjawiska stosowania tej metody badawczej, jest artykuł J. Stewarda [2012] pt.: Multiple-case study methods in governance - related research. Należy również dodać, że studium przypadku jako metoda badań jest szczególnie lubiana przez autorów z zakresu zarządzania rozwojem terytorialnym czy marketingu terytorialnego. Większość opracowań dotyczących tego ostatniego, publikowanych w takich uznanych czasopismach naukowych, jak: ,Journal of Place Management and Development” czy „Place Branding”, wykorzystuje właśnie studium przypadku jako podstawową metodę badań.

\section{Koncepcja badań relacji międzyorganizacyjnych w marketingowym procesie budowania marki terytorium w oparciu o kulturę}

Celem badań jest identyfikacja determinant wpływających na skuteczną współpracę władz samorządowych (miasta i regionu) z instytucjami kultury w celu kreowania marki terytorialnej w oparciu o kulturę. Projekt ma też na celu określenie motywów nawiązywania i utrzymywania relacji współpracy na lokalnym rynku kultury.

Do projektowanego badania zdecydowano się zastosować procedurę prowadzenia studium przypadku, zaproponowaną przez Roberta K. Yina, dostosowując ją do specyfiki badania procesów rynkowych w organizacjach publicznych. Na schemacie (rys. 1) pokazano kolejne etapy tego procesu, z których najważniejsze zostaną następnie przybliżone. 


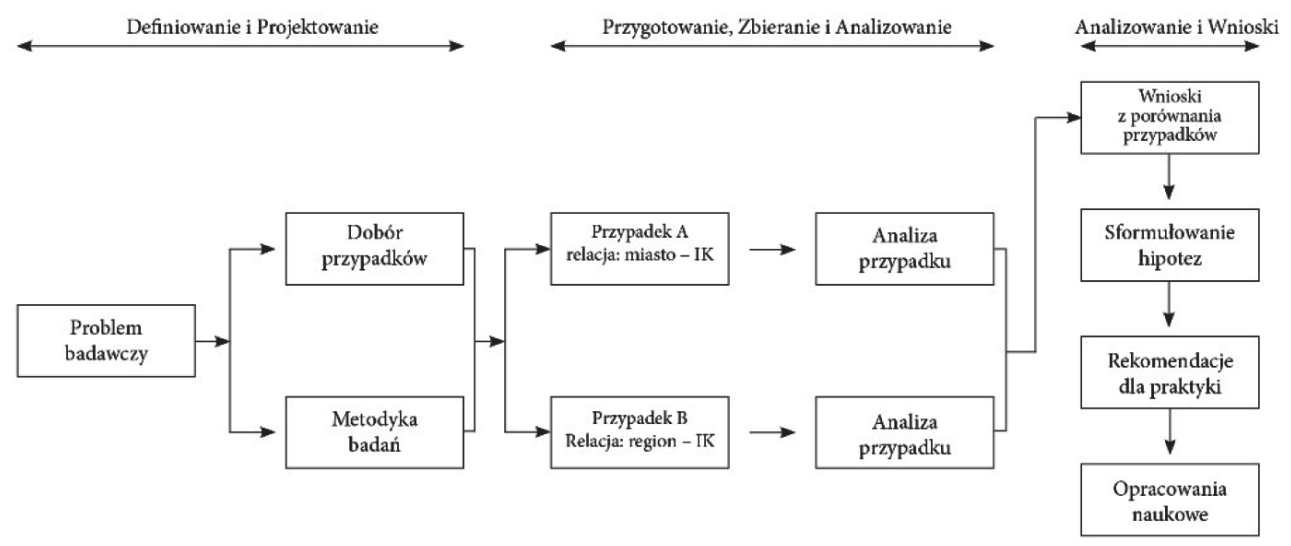

Rys. 1. Etapy procedury badawczej bazującej na metodzie studium przypadku relacji administracji publicznej z instytucjami kultury (podejście indukcyjne)

Źródło: opracowanie własne na podstawie: [Yin 2009].

\subsection{Faza projektowania badań}

\subsubsection{Formułowanie pytań badawezych}

W opisywanym projekcie badawczym przyjęto trzy główne pytania badawcze:

1. Jaki jest wpływ procesów marketingowych podejmowanych przez administrację publiczną na relacje międzyorganizacyjne pomiędzy podmiotami publicznymi na rynku kultury?

2. Jakie są motywy współpracy międzyorganizacyjnej na rynku publicznych instytucji kultury w środowisku lokalnym i regionalnym?

3. Jak angażować miejskie i regionalne instytucje kultury do współpracy na rzecz skuteczności procesu budowania marki terytorium opartej na zasobach kultury?

Projekt uwzględnia fakt, że na terenie miasta działają miejskie i regionalne struktury samorządowe podejmujące równoległe działania na rzecz zaspokojenia potrzeb mieszkańców w zakresie kultury. Struktury te podlegają oddzielnym władzom samorządowym (wojewódzkim i miejskim), a w wymiarze prawno-administracyjnym działają niezależnie. Należy podkreślić, że nie ma też przesłanek formalnych do podejmowania współpracy. Natomiast współpraca zasadna jest w wymiarze funkcjonalnym. Oferta zarówno wojewódzkich, jak i miejskich instytucji kultury kierowana jest przecież do podobnego audytorium, a procesy budowania konkurencyjności układów funkcjonalnych - miejskich, aglomeracyjnych, regionalnych uzasadniają, a wręcz wymagają współdziałania dla osiągania wspólnych korzyści przy realizacji celów społecznych. 


\subsubsection{Badane przypadki i jednostki analizy}

Przyjęto, że badanie ma zidentyfikować nowe czynniki, fakty, zjawiska, które pozwolą jako wynik prowadzonych rozważań sformułować hipotezy, czyli przypuszczalne prawidłowości odnoszące się do badanych zjawisk. Oznacza to, że zgodnie z logiką indukcyjną nie przewidziano formułowania hipotez badawczych na początku badania, co byłoby uzasadnione przy podejściu ilościowym (dedukcyjnym). W projekcie przyjęto dwa przypadki odnoszące się do kontekstu budowania marki terytorialnej:

Przypadek A: Relacje administracji miejskiej.

Przypadek B: Relacje administracji wojewódzkiej.

W każdym z tych przypadków zidentyfikowane zostały trzy relacje stanowiące osadzone (w kontekście kultury) jednostki analizy:

1. Administracja miasta centralnego/regionu - instytucje kultury, dla których dana jednostka samorządu terytorialnego jest organem prowadzącym.

2. Administracja miasta centralnego/regionu - instytucje kultury podlegające pod inne jednostki samorządu terytorialnego, funkcjonujące $\mathrm{w}$ przestrzeni miasta centralnego.

3. Administracja regionu - administracja miasta centralnego.

Relacje te będą analizowane w kontekście realizacji procesów budowania marki terytorium. Warto podkreślić, że koncepcje budowania marki zarówno w przypadku miasta, jak i regionu stwarzają możliwość umieszczania w treści przekazów tematyki kultury. Miasto Łódź przyjęło bowiem koncepcję budowania marki w oparciu o „Przemysły Kreatywne”, natomiast województwo łódzkie otworzyło treść przekazów na wszystko, co jest cenne i stanowi o tożsamości tego regionu. Dokonano tego poprzez wykorzystanie formuły „Łódzkie Promuje”, umożliwiającej włączanie w promocję województwa różnych mniejszych jednostek oraz wydarzeń czy innych charakterystycznych dla tożsamości regionu przedsięwzięć.

\subsubsection{Kryteria interpretacji wyników i interdyscyplinarność analizy}

Każdy z podjętych przypadków będzie zanalizowany z uwzględnieniem jego kontekstu (organ prowadzący, strategia rozwoju kultury, strategia budowania marki miasta/regionu, cele dla odpowiednio: regionalnych i miejskich IK, podejmowane działania marketingowe terytorium i stopień włączania w nie IK).

Kryteria różnicujące oba przypadki to odmienny proces marketingowy prowadzony przez odpowiednio: administrację województwa (Departament Promocji) oraz administrację miasta (Biuro Promocji), także odrębna polityka rozwoju kultury rozumiana jako strategia rozwoju tej dziedziny dla terytorium, odpowiednio: dla regionu i dla miasta. W nawiązaniu do wymiaru teoretycznego rozważań, odnoszącego się do modelu zarządzania publicznego w organizacji terytorialnej, w przypadku regionu przyjęto filozofię partycypacyjną (filozofia design thinking), natomiast 
w przypadku miasta proces budowania marki był oparty na relacjach rynkowych, czyli kontraktach z dostawcami usług marketingowych.

\subsection{Przygotowanie, zbieranie $i$ analizowanie informacji}

W projekcie przygotowano cztery scenariusze wywiadu kierowane do następujących grup docelowych: menedżerowie w administracji miejskiej i wojewódzkiej zajmujący się problematyką promocji i kultury oraz menedżerowie miejskich i wojewódzkich instytucji kultury mających swoją siedzibę w Łodzi. Starano się jednak, aby wspomniane scenariusze miały możliwie wiele elementów wspólnych, umożliwiających zarówno śledzenie opinii na tematy dotyczące relacji na lokalnym rynku kultury, jak i opinii z wyodrębnionych dwóch perspektyw (administracja samorządowa $\mathrm{i}$ instytucje kultury).

W ramach podjętych studiów przypadków zaplanowano również pozyskanie informacji w postaci dokumentów pierwotnych (strategie, plany, raporty, rejestry projektów dofinansowanych itp.) oraz prowadzenie obserwacji uczestniczących (lokalne wydarzenia kulturalne).

\subsection{Analizowanie i wnioski}

Spośród kilku technik analitycznych polecanych do studium przypadków zdecydowano się na dobór techniki: budowanie wyjaśnień (explanation building) [Yin 2009, s. 141]. Jej celem nie jest wyprowadzenie ostatecznych wniosków z badania, ale wypracowanie hipotez, czyli prawdopodobnych odpowiedzi na postawione pytania badawcze, które mogą być następnie przedmiotem testowania w procesie badań ilościowych na szerszej grupie przypadków.

Badane relacje będą analizowane w przyjętej kolejności. Najpierw zostanie opisana relacja pionowa: administracja samorządowa - instytucja kultury dla każdego $\mathrm{z}$ analizowanych przypadków (A i B). Zostanie tu podjęta obserwacja obu stron (jednostka w urzędzie ds. kultury versus IK). Ma to na celu ustalenie, w jakim stopniu jest to relacja hierarchiczna, a w jakim partnerska. Pozwoli to na zdiagnozowanie, czy pod tym względem istnieją różnice pomiędzy przypadkami A i B oraz na czym te różnice polegają. Następnie podjęta zostanie obserwacja wypowiedzi respondentów w zakresie procesów budowania marki i stopnia zaangażowania w nie IK. Określony zostanie stopień uczestniczenia odpowiednio: miejskich IK i wojewódzkich IK w tym procesie. Szczególnie interesujące będzie zaobserwowanie postaw oraz innych czynników mających wpływ na relacje administracji miasta przypadku A z wojewódzkimi IK z przypadku B.

\section{Zakończenie}

Studiowanie przypadków to metoda badań interpretatywnych, która posiada wartość eksplanacyjną, szczególnie ważną dla zrozumienia złożonych zjawisk w naukach 
społecznych, w tym naukach o zarządzaniu. Metoda ta przyczynia się do bogatszej obserwacji i możliwości lepszego zrozumienia dynamicznej rzeczywistości funkcjonowania współczesnych organizacji publicznych.

Wyjściowym problemem badacza staje się sformułowanie pytania badawczego i przyjęcie założeń jednego z paradygmatów do poszukiwania na nie odpowiedzi. Po wyborze specyficznego przypadku (lub przypadków) badacz dokonuje kompleksowej analizy uwarunkowań zachodzących w przedmiocie badania. W przypadku metody case study sama procedura badawcza jest wbrew obiegowym opiniom wysoce ustrukturalizowana i wymaga dużo większego wysiłku badaczy.

Zastosowanie sprzężeń zwrotnych w procedurze badawczej, wymuszających konfrontację poszczególnych etapów badania z dostępną literaturą, pozwala natomiast na sformułowanie naukowych uogólnień, które mogą stanowić nowy wkład w badaną problematykę. Studium przypadku wydaje się metodą pozwalającą na odkrycia naukowe zwłaszcza w procesach, które mają złożony, interdyscyplinarny charakter.

\section{Literatura}

Agranoff R., Radin B.A., 1991, The comparative case study approach in public administration, Research in Public Administration, 1, s. 203-231.

Anders-Morawska J., Rudolf W., 2015, Orientacja rynkowa we wspótrządzeniu miastem, Wydawnictwo Uniwersytetu Łódzkiego, Łódź.

Doyle P., 2003, Marketing wartości, Wydawnictwo Felberg SJA, Warszawa.

Dul J., Hak T., 2008, Case Study Methodology in Business Research, Elsevier, Oxford.

Eisenhardt K.M., 1989, Building theories from case study research, Academy of Management Review, 14,4 , s. 532-550.

Glińska E., 2016, Budowanie marki miasta. Koncepcje, warunki, modele, Wolters Kluwer, Warszawa.

Glińska E., 2017, Angażowanie interesariuszy w proces brandingu miasta - teoria versus praktyka, Zarządzanie Publiczne, nr 2(40), s. 33-49.

Kavaratzis M., 2004, From city marketing to city branding: Toward a theoretical framework for developing city brands, Place Branding, 1 (1), s. 58-73.

Kavaratzis M., 2012, From "necessary evil” to necessity: stakeholders' involvement in place branding, Journal of Place Management and Development, 5 (1), s. 7-19.

Klijn E.H., Eshuis J., Braun E., 2012, The influence of stakeholder involvement on the effectiveness of place branding, Public Management Review, 14 (4), s. 499-519.

Łapczyński M., 2010, Wartość dla klienta - przegląd wybranych koncepcji z ostatniego dwudziestolecia, [w:] Figiel Sz. (red.), Marketing w realiach wspótczesnego rynku. Strategie i działania marketingowe, PWE, Warszawa, s. 73-74.

Patton E., Appelbaum S., 2003, The case studies in management research, Management Research News, vol. 26, no. 5, s. 60-71.

Perry C., 1998, Processes of a case study methodology for postgraduate research in marketing, European Journal of Marketing, vol. 32, no. 9/10, s. 75-80.

Rudolf W., 2016, Marketing terytorialny w ujęciu relacyjnym, Wydawnictwo Uniwersytetu Łódzkiego, Łódź. 
Smith J.B., Colgate M., 2007, Customer value creation: A practical framework, Journal of Marketing Theory and Practice, vol. 15, no. 1.

Stake R.E., 1995, The Art of Case Study Research, SAGE Publications, Thousand Oaks, CA.

Stein H., 1952, Case method and the analysis of public administration, [w:] Stein H. (ed.), Public Administration and Policy Development, Harcourt Brace Jovanovich, New York.

Steward J., 2012, Multiple-case study methods in governance - related research, Public Management Review, vol. 14, issue 1.

Strategia zarządzania marką Łódź na lata 2010-2016, s. 17-24.

Sudoł S., 2012, Nauki o zarzadzaniu. Podstawowe problemy kontrowersje i propozycje, Polskie Wydawnictwo Ekonomiczne, Warszawa.

Sullivan H., Skelcher C., 2002, Working Across Boundaries. Collaboration in Public Services, Palgrave Macmillan, New York.

Yin R.K., 2009, Case Study Research Design and Methods, SAGE, London. 